\title{
Correlation between optimal carsharing locations and carbon dioxide emissions in urban areas
}

\author{
J.-B. Lee $\cdot$ W. Byun $\cdot$ S. H. Lee $\cdot$ M. Do
}

Received: 12 December 2013/Revised: 7 May 2014/ Accepted: 30 June 2014/Published online: 23 July 2014

(C) Islamic Azad University (IAU) 2014

\begin{abstract}
Carsharing, an alternative to car ownership, is being encouraged by many national governments as a means to alleviate air pollution and traffic congestion. Previously, many carsharing companies determined service locations through trial and error, but they currently define their parking locations in metropolitan cities for maximum customer coverage. However, identifying carsharing locations according to the experiences of the pioneering cities might not yield valid results in some Asian countries where carsharing systems are unknown. Hence, this study examines the characteristics of carsharing users in Daejeon, a small Korean city, to determine that city's optimal carsharing service locations. A geographic information system was used to analyze and determine the best spatial areas according to two data categories: internal and external demand factors. Suitable carsharing locations were ranked by the results of a grid analysis. Thirty optimal locations were then determined from the location-allocation model in a network analysis module. Determining optimal
\end{abstract}

J.-B. Lee

Daejeon Development Institute, 85, Jungang-Ro, Jung-Gu, Daejeon 301-763, Korea

W. Byun

Urban Planning and Architecture Division, Land and Housing Institute (LHI), 462-2, Jeonmin-Dong, Yusong-Gu, Daejeon 305-731, Korea

S. H. Lee

U-City Research Cluster, Construction and Transportation Information Center, Hanbat National University, 16-1, Dukmyung-Dong, Yusong-Gu, Daejeon, Korea

M. Do (ه)

Department of Urban Engineering, Hanbat National University, 16-1, Dukmyung-Dong, Yusong-Gu, Daejeon 305-719, Korea e-mail: msdo@hanbat.ac.kr carsharing locations should also be directly correlated with the reduction of carbon dioxide emissions. Carbon dioxide emission reduction from carsharing was predicted at 62,070 tCO2eq for the year 2013; emission reductions were predicted to increase further to 172,923 tCO2eq by 2020 . Thus, carsharing is an innovative strategy for traffic demand management that can alleviate air pollution. The results of this study indicate that further research is necessary to examine the relationship between optimal carsharing locations and carbon dioxide emission reduction from using lower-emission carsharing vehicles, such as electric vehicles.

Keywords Carsharing - Carbon dioxide emission . Correlation analysis · Geographic information system

\section{Introduction}

Previously, people would ride bicycles that they owned. However, they do not do so anymore because bike sharing has become commonly available near subways, universities, and commercial areas, especially in many urban areas. Presently, people rent a bicycle to travel short distances and then return it. This change indicates a shift from bicycle ownership to bicycle sharing. Similarly, carsharing could potentially replace car ownership and could be made an "anywhere and at anytime" service. Carsharing, an alternative to car ownership, is being encouraged by many national governments, including those of the USA and Europe, as a means to alleviate air pollution and traffic congestion (Shaheen et al. 2002; Martin and Shaheen 2011; Litman 2000). Despite the availability of public transportation systems such as buses, subways, and trams, people still prefer to travel by car as it is more comfortable and 
convenient. Carsharing affords two benefits: the convenience of a personal car and a low price compared with traditional car rental. Carsharing is a new and innovative transportation system that can easily be made available to people in high-density areas. Therefore, it has rapidly grown throughout metropolitan areas in North America and Europe (Shaheen and Cohen 2007). The number of carsharing members in North America increased from 25,640 in 2003 to 279,174 in 2008 (Shaheen et al. 2009). Leveque and Moosa (2013) estimated the numbers of carsharing members and vehicles worldwide at 3 million and 70,000, respectively, as of 2013; they predicted a further increase in the number of members to 26.2 million by 2020 . Zhao (2010) predicted that the number of carsharing members would increase to 4.4 million and 5.5 million in North America and Europe, respectively, by 2016.

Previous studies on carsharing mostly focused on evaluating benefits in terms of traffic demand management and greenhouse gas emission reduction (Litman 2000; Cervero and Tsai 2004; Catalano et al. 2008; Martin and Shaheen 2011; Rodier and Shaheen 2003; Liao et al. 2013). Cervero and Tsai (2004) estimated the extent to which carsharing reduces car ownership and traffic volume. Martin and Shaheen (2011) evaluated the effect of carsharing on greenhouse gas emissions by monitoring the lifestyle changes of carsharing members. Rodier and Shaheen (2003) evaluated the extent to which carsharing affects vehicle emission reduction, as well as its economic benefits. Several recent studies have examined carsharing users' behavior and demand modeling. Costain et al. (2012) investigated carsharing members' behavior using a dataset on carsharing in Toronto. Accessibility is one of the most important factors, and membership varies with increasing parking lot size. In addition, more than $60 \%$ of carsharing members traveled less than $40 \mathrm{~km}$ per year. Jorge and Correia (2013) reviewed previous studies on demand estimation in carsharing systems. Many demand modeling studies had explored vehicle relocation to balance one-way carsharing systems rather than round trips. Correia and Antunes (2012) performed an optimization study for depot locations in one-way carsharing systems. They used mixed-integer programming models as a profit-maximizing optimization approach.

However, most studies are yet to adequately address location determination issues. Although location determination is a factor that directly affects the sustainability of carsharing services, only a few studies have focused on methods to identify optimal carsharing locations. Ion et al. (2009) investigated optimal locations for electric carsharing services by modeling user preferences. Celsor and Millard-Ball (2007) analyzed potential carsharing locations by using a geographic information system (GIS) tool, based on the characteristics of existing locations. Determining optimal carsharing locations is very important, because it can result in maximizing carsharing operational rates. As previously mentioned, Martin and Shaheen (2011) suggest that carsharing can directly change lifestyle choices, leading in turn to a reduction in greenhouse gas emissions, particularly carbon dioxide $\left(\mathrm{CO}_{2}\right)$. Thus, the correlations between optimal carsharing locations and $\mathrm{CO}_{2}$ emission reduction need to be studied.

In the early stages, most carsharing companies determined their service locations through trial and error. Now, economically viable carsharing locations in a metropolitan city such as New York, San Francisco, or Paris can be easily determined according to the pioneering cities' model. Such cities generally have a high population density, various public transportation systems, and excellent traffic networks; moreover, the indicators for determining carsharing locations are similar. However, identifying carsharing locations according to the experiences of pioneering cities may not yield sustainable and profitable results for carsharing companies in a smaller city or in some Asian countries where carsharing systems are unknown. One reason for this is the fact that carsharing users in Asian countries, including Korea, have different characteristics. For example, accessibility to carsharing locations is one of the most important factors for the sustainability of carsharing services in pioneering metropolitan cities. However, small- and medium-sized cities generally have lowquality public transportation systems with long allocation times, and some areas have a low population density. Both of these factors are obstacles to determining optimal carsharing locations. In addition, even though carsharing has become common in North America and Europe, it is still an unfamiliar concept in most Asian countries. Most Asians are not comfortable with sharing a vehicle. However, this situation is likely to change, albeit slowly. China has started encouraging carsharing as an innovative transportation method with environmental and social advantages (Shaheen and Martin 2010). Therefore, a more systematic approach is necessary to determine optimal service locations for making carsharing sustainable and profitable. This study investigates the characteristics of Daejeon, an urban city in Korea, and identifies the best carsharing locations using a GIS tool. In addition, we have calculated $\mathrm{CO} 2$ emission reductions from carsharing when operation rates are maximized.

\section{Materials and methods}

General carsharing survey results

\section{Distribution of carsharing usage time}

In Korea, carsharing was introduced in 2008. As of 2012, six carsharing companies operate in Korea. For this study, 
Fig. 1 Percentage of carsharing users according to rental time

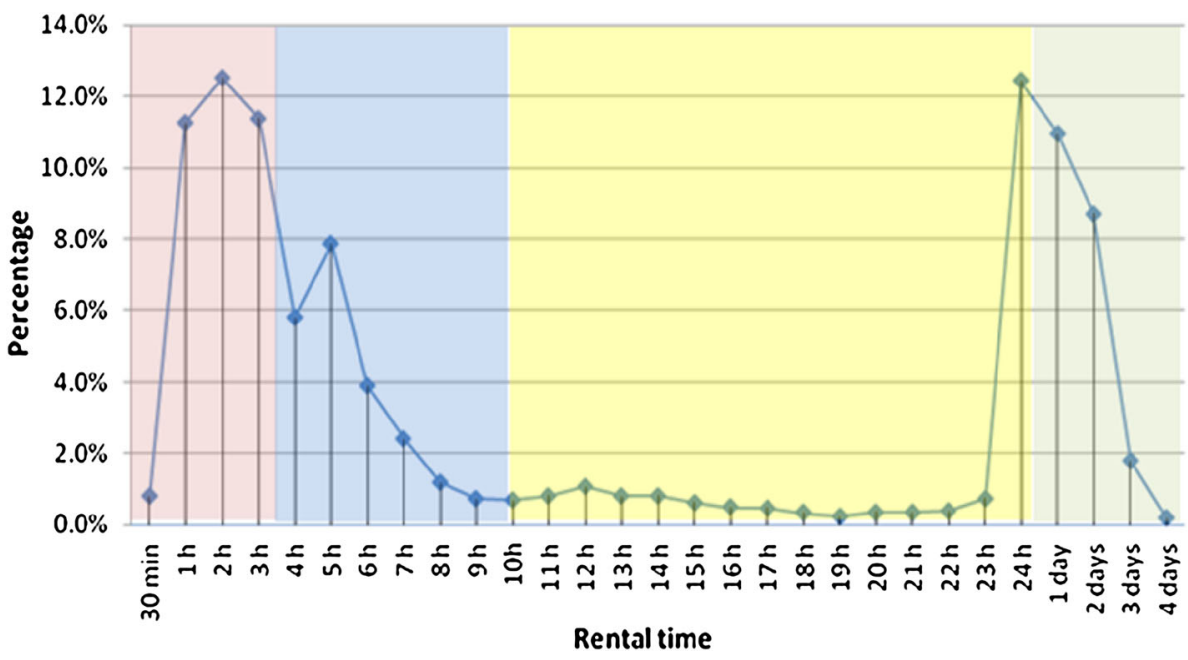

\begin{tabular}{c|c|c}
\hline & Frequency & Percentage \\
\hline Commute & 22 & 3 \\
\hline Shopping & 40 & 6 \\
\hline Business & 139 & 21 \\
\hline Dating & 196 & 30 \\
\hline Short-distance trip & 182 & 28 \\
\hline Others & 82 & 12 \\
\hline
\end{tabular}

Fig. 2 Carsharing purposes

we obtained data for 5 months from Green Point, one of the most successful carsharing companies in Korea. Green Point's marketing team conducted a survey from October 1, 2011, to February 28, 2012, targeting people who had experienced carsharing. They obtained 661 valid responses from among 15,865 members. The data collected enabled us to analyze the characteristics of carsharing users.

The main distinction between carsharing and traditional car rental is that, in the latter case, cars are rented for a minimum of $24 \mathrm{~h}$. The survey results of this study suggest that $35.9 \%$ of carsharing users in Korea rent a car for less than $3 \mathrm{~h}$, which is a relatively short period considering US data. For example, some $90 \%$ of City CarShare members in San Francisco normally rent a car for $<5 \mathrm{~h}$ (Cervero and Tsai 2004). Furthermore, a significant percentage of carsharing members in Korea rent a vehicle for more than 1 day: $11.0 \%$ rent for 1 day and $8.7 \%$, for 2 days (Fig. 1). These results suggest that many carsharing members in Korea are yet to differentiate traditional car rental from carsharing. However, some members consider it more convenient to reserve and use a shared car than to interact with classical renting companies.

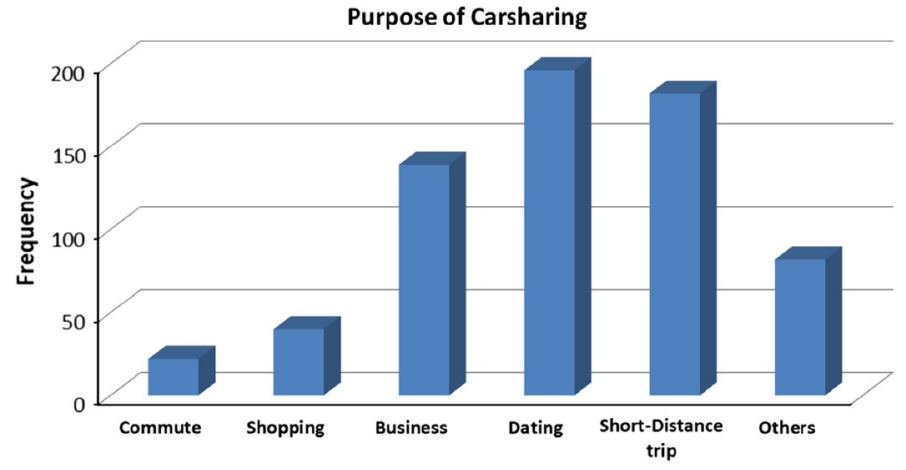

\section{Carsharing purposes}

Traditional car rental is often used for business travel or long-distance journeys. By contrast, in carsharing, cars are rented on an hourly basis and are used for short-distance trips $(28 \%)$, shopping $(6 \%)$, or going on a date $(30 \%)$. However, they are rarely used for commuting (Fig. 2). Of the respondents, $67.1 \%$ use their own vehicles to commute, indicating that carsharing is not a substitute for primary car ownership.

\section{Convenient and inconvenient elements for using carsharing}

The convenient and inconvenient elements involved in the use of carsharing were investigated. We found that $29 \%$ of respondents use carsharing because hourly rentals are possible. Further, $24 \%$ use it because of the convenience of reservation and use. Meanwhile, $25 \%$ of respondents reported that the most inconvenient aspect of carsharing is that the vehicle has to be returned to the same place. In addition, elderly people, who are not familiar with hightech devices, found it inconvenient to make reservations 
Table 1 Reasons for using carsharing and inconvenient elements of carsharing

\begin{tabular}{|c|c|c|c|c|c|}
\hline Reason for using carsharing & Frequency & Percentage & Inconvenient elements of carsharing & Frequency & Percentage \\
\hline Hourly rent & 349 & 29 & Two-way return & 264 & 25 \\
\hline Convenient reservation and usage & 292 & 24 & Inconvenient reservation & 171 & 16 \\
\hline Relatively cheaper than personal vehicle & 237 & 20 & Search for a vehicle in the parking lot & 166 & 15 \\
\hline Necessity of business vehicle & 148 & 12 & High cost & 136 & 13 \\
\hline Reducing air pollution & 51 & 4 & Dirty interiors of vehicle & 101 & 9 \\
\hline Using various types of vehicles & 47 & 4 & Dirty exteriors of vehicle & 74 & 7 \\
\hline Extra vehicular needs & 37 & 3 & Parking fee & 56 & 5 \\
\hline Lack of parking lot & 20 & 2 & Use of card to open and lock a vehicle's door & 37 & 3 \\
\hline Many people share a vehicle & 7 & 1 & Filling gas & 21 & 2 \\
\hline Others & 25 & 2 & Others & 50 & 5 \\
\hline
\end{tabular}

(Table 1). Interestingly, a high percentage of respondents either liked or did not like the reservation system. The survey results suggest that the reservation system needs to be modified to make it user-friendly for various age groups and that more vehicles should be available for one-way services.

\section{Indicators for ideal carsharing locations}

The investigation of key indicators is very significant in realizing a sustainable and profitable carsharing business. Kim (2012) investigated the relationship between the distribution of Zipcar parking lots and factors such as the distributions of population density, vehicle ownership, household income, and areas with accessibility to better and more affordable transportation systems. Celsor and Millard-Ball (2007) investigated the economic viability of carsharing by analyzing carsharing locations in the pioneering cities. However, in the absence of carsharing data for most Asian countries and small local small cities, various important indicators need to be considered to establish successful carsharing services.

\section{Land price}

Household income is normally an important consideration for successful carsharing businesses. Martin and Shaheen (2011) compared the household income distribution of carsharing users in the USA and Canada. Both distributions were approximately equal. The median interval was about $\$ 50,000$ to $\$ 60,000$, and more than $50 \%$ of the users had a household income above $\$ 60,000$. However, unlike in North America and Europe, data on carsharing in Korea are relatively scarce. Despite the importance of household income, we were unable to use it as a significant factor. Instead, we have assumed that land price is closely related to household income, as people who live on higher-priced land are more likely to have a higher household income.

\section{Distribution of carsharing members}

Figure 3 shows that the carsharing age distributions of Korea and the USA are similar, with 25-35 years being the largest age group in both cases. In Fig. 3, the distribution is skewed to the right, implying that older people are less likely to opt for carsharing. However, carsharing in the USA is more widely distributed, that is, the percentage of users in the group aged 26-35 years in Korea is higher than in the USA (Martin and Shaheen 2011). Thus, places with large numbers of young adults, such as universities or commercial areas, may be ideal locations.

\section{Accessibility from outside the city}

Railway stations and bus terminals with a large number of commuters are important locations for carsharing. Many commuters from other areas normally use other public transportation systems, such as buses or subways. However, public transportation is convenient only if it covers the entire city and if commuters are aware about the various means of transportation available for their destination. Thus, many commuters from outside the city use taxis or drive to the city in their own personal cars. Carsharing makes it easy and inexpensive to travel for business purposes. Carsharing members normally do not drive their own vehicle for intercity travel, because they could use a carsharing vehicle as a personal car in the city.

\section{General indicators}

Although ideal carsharing locations vary according to the characteristics of each country, areas near subway stations, government offices, and universities are generally considered good locations. University students usually have a driver's license, but not a car because they cannot afford to own one. Nevertheless, they sometimes need one to go on a date or on a trip with friends. Thus, it is also important to 
Fig. 3 Comparison of carsharing user age distributions in Korea and the USA
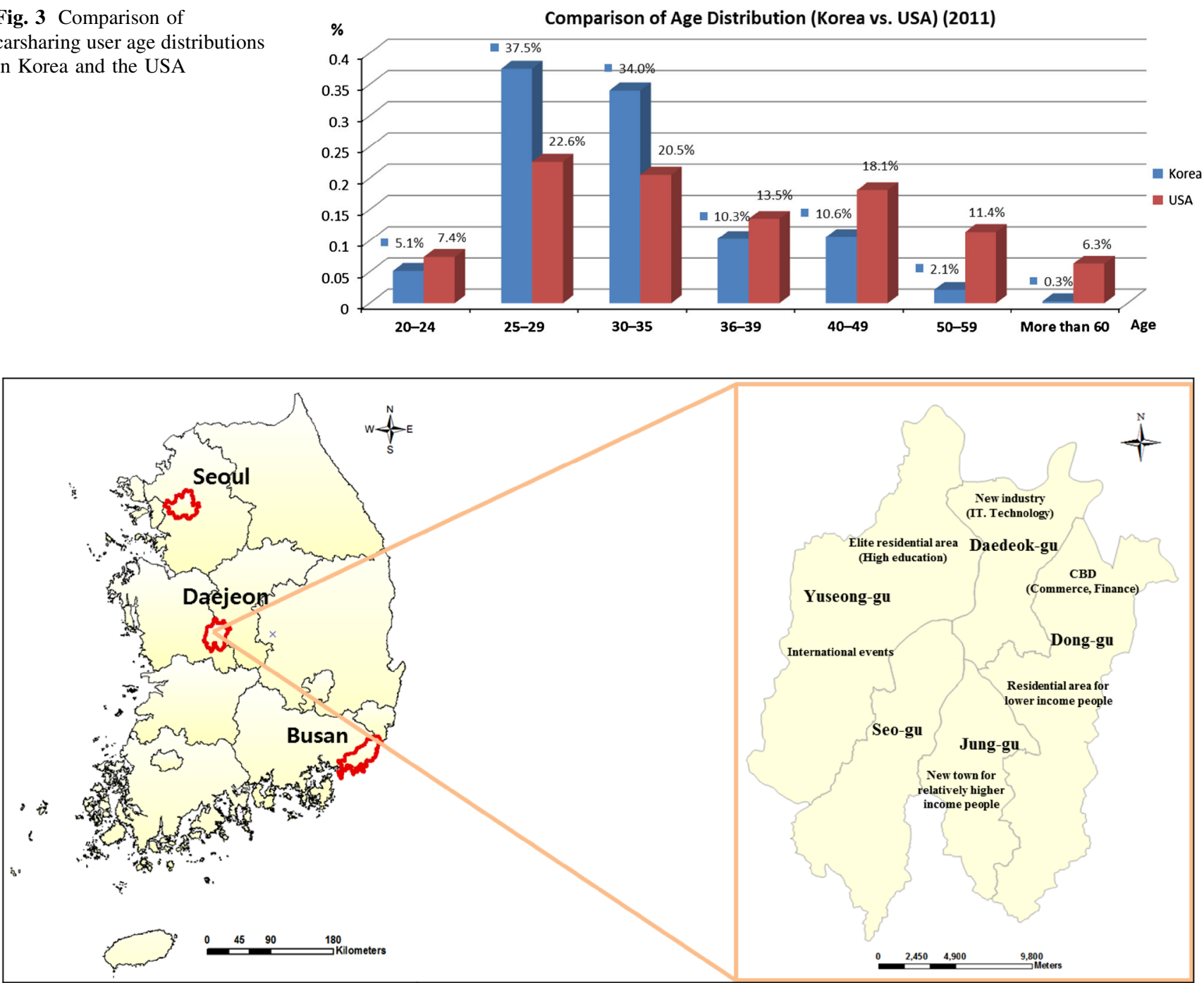

Fig. 4 Map of Daejeon, the case study area

consider locations near universities. In addition, high population density areas such as commercial areas commonly provide various types of public transportation systems in easily accessible locations. Carsharing users in such areas are more likely to choose carsharing over other alternatives.

\section{Results and discussion}

Study area

Daejeon, an urban Korean city, was selected for this case study (Fig. 4). Daejeon has a population density of 2,535/ $\mathrm{km}^{2}$, the sixth highest in Korea. It has five boroughs: Dong$\mathrm{Gu}$, a commercial and financial center; Jung-Gu and Seo$\mathrm{Gu}$, residential areas; Daedeok-Gu, an information technology (IT) center; and Yuseong-Gu, a green area and a venue for international events. Typically, people belonging to the higher-income groups live in Jung-Gu, Seo-Gu, and Yuseong-Gu, whereas those belonging to the lower-income groups live in Dong-Gu. Residents of Yuseong-Gu value higher education very much because most of them have higher educational qualifications. Daedeok-Gu and Dong$\mathrm{Gu}$ are both well-known new industry and business areas.

GIS analysis for determining optimal carsharing locations

\section{Building base data for GIS analysis}

To investigate optimal carsharing locations, grid analysis was performed by GIS, which is a useful tool to analyze and determine the best spatial areas for a certain purpose using geographical data. Vlachopoulou et al. (2001) used the GIS tool to select warehouse sites. Atabi et al. (2013) 


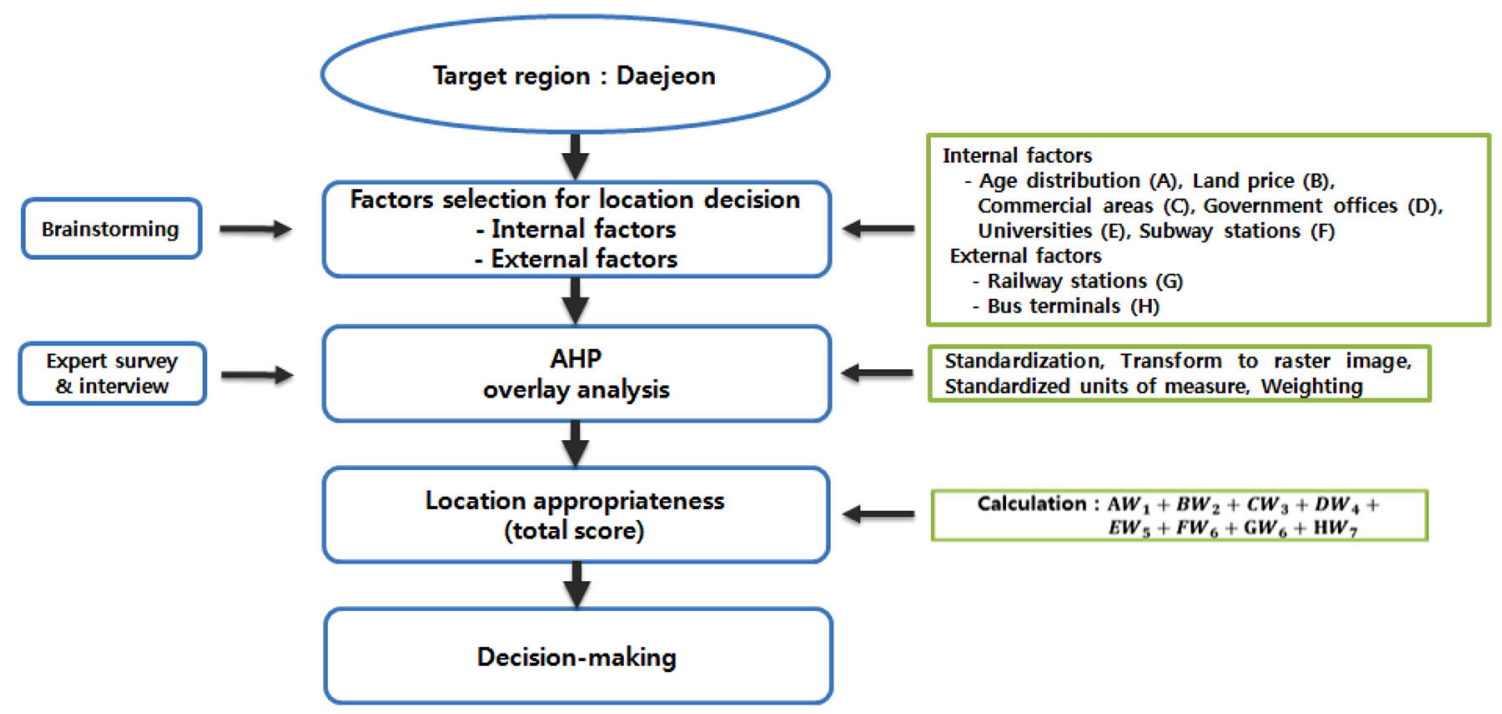

Fig. 5 Process for identifying carsharing locations

investigated levels of benzene concentration produced from vehicles and gas stations at Tehran in Iran by using the GIS tool. The data for this study were classified into two categories for grid analysis: internal demand factors and external demand factors. Eight indicators were used to standardize the units of measure and transform the area into a matrix of cells (Fig. 5). Then, the data were weighted based on the proportion of cells within a walking sphere of $500 \mathrm{~m} \times 500 \mathrm{~m}$. Through overlay analysis, optimal carsharing locations were determined. Figure 5 shows the process for identifying those locations. In the calculation, $W_{i}$ indicates the weight based on the proportion of cells within the $500 \mathrm{~m} \times 500 \mathrm{~m}$ area. The values were calculated by multiplying each indicator by its weight.

Figure 6 shows the distribution of spatial elements, such as population distributions of ages between 25 and 35 years, land price, commercial areas, government offices, universities, subway and railway stations, and bus terminals. Daejeon has only one subway line and insufficient city bus lines. Commercial areas are dispersed around the city. In contrast, the city has relatively many universities with 0.1 million students out of a population of 1.5 million. Compared with the other boroughs, Jung-Gu, Seo-Gu, and Yuseong-Gu have a high percentage of households.

\section{Analytic hierarchy process for standardization}

The analytic hierarchy process (AHP) technique was adopted to analyze complex decisions. The AHP helps decision makers to determine options that would best suit their goal. Nouri et al. (2013) made environmental decisions for new towns using the AHP model. Tuzkaya (2009) applied fuzzy-AHP methodology to consider the environmental effects of transportation modes. The preference- ranking organization method for enrichment evaluation was used to rank transportation modes. In this paper, the AHP model was used to reflect the relative importance of indicators, which may affect optimal carsharing locations. Figure 7 shows the results of the survey, eliminating more than 0.15 of the consistency ratio (CR). A CR of no more than 0.15 indicates that respondents performed pairwise comparisons of elements consistently. Here, the CR is calculated from the relationship between the consistency index and the random consistency index. On the basis of the AHP results, age distribution and commercial areas (as internal demand factors), as well as railway stations and bus terminals (as external demand factors), proved to be more important than others.

$$
\begin{aligned}
& \mathrm{CI}=\frac{\lambda_{\max }-N}{N-1} \\
& \mathrm{CR}=\frac{\mathrm{CI}}{\mathrm{RI}}
\end{aligned}
$$

Here, CI: consistency index, $\lambda_{\max }$ : $\max$ eigenvalue, $N$ : size of matrix, RI: random consistency index.

Optimal carsharing locations

With these spatial elements, every cell was ranked by overlay analysis. Then, the location-allocation model in the network analysis module was adopted to determine 30 optimal locations. This paper adopted the minimize weighted impedence (p-median) model to determine optimal carsharing service locations. This model determines the optimal carsharing locations with the minimum total distance between carsharing users and 30 locations on the assumption that all users use the minimum-distance vehicle. The equation is represented below (Chan 2004): 


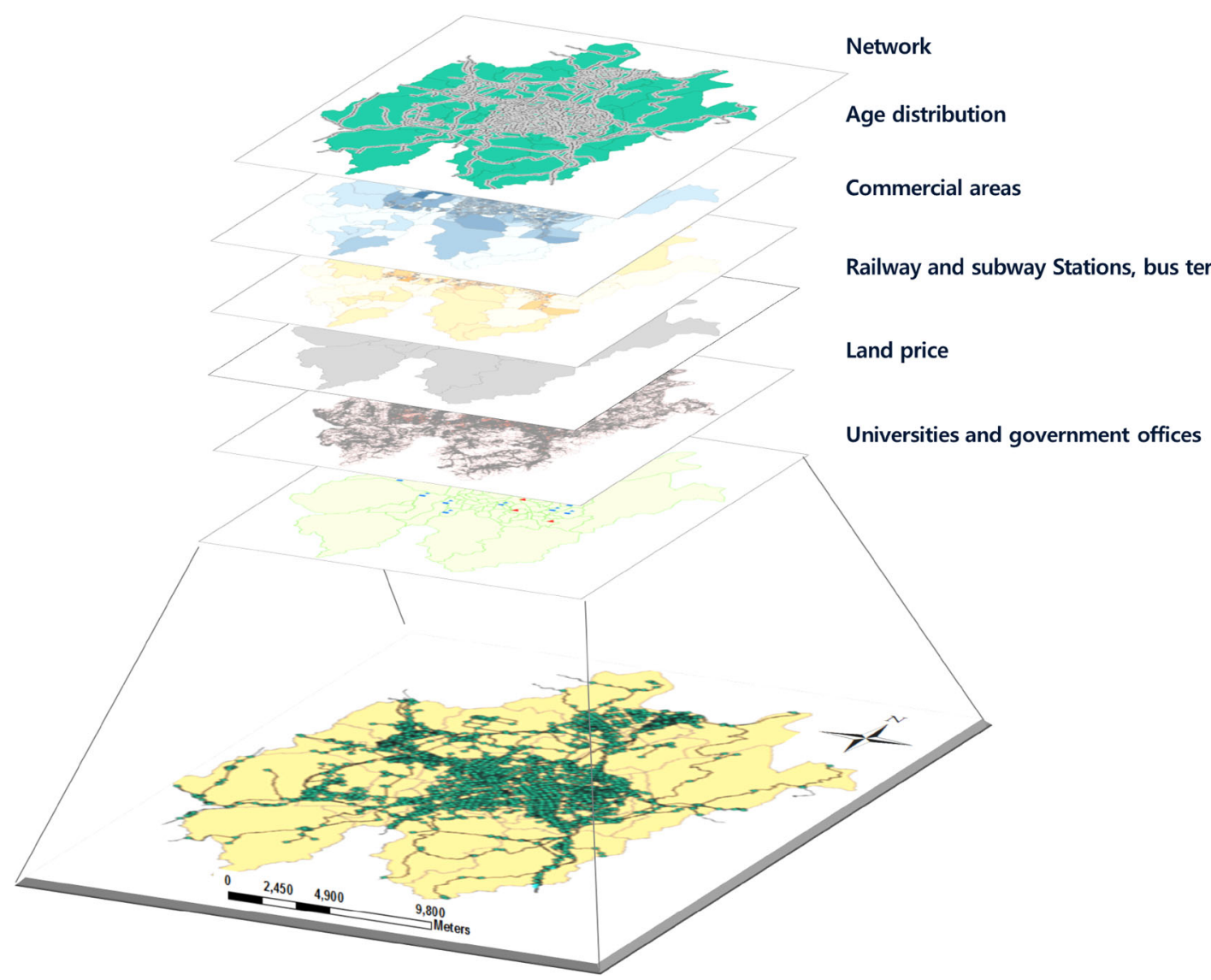

Fig. 6 Distributions of spatial elements

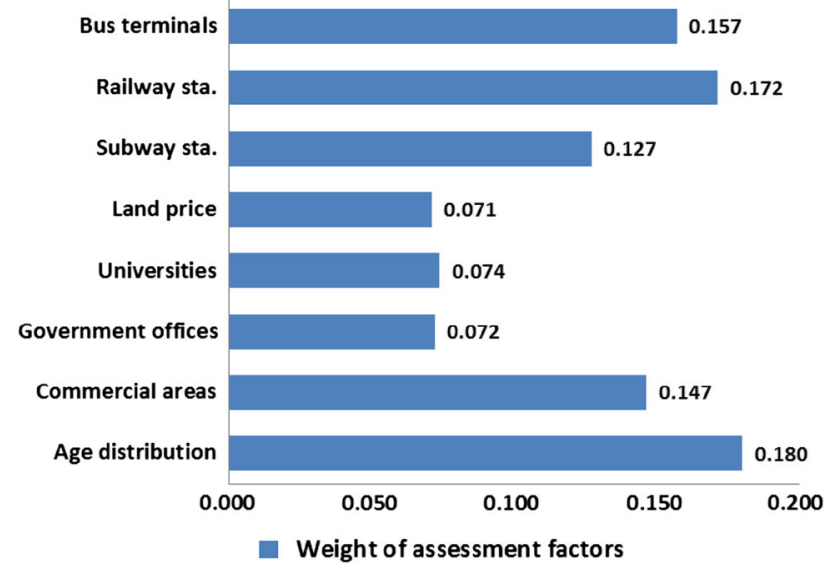

Fig. 7 Weight of assessment indicators

$\operatorname{Min} \mathrm{Z}=\sum_{i \in I} \sum_{j \in I} f_{i} d_{i j} x_{i j}$

Here, s.t. $\sum_{j \in I} x_{i j} \geq 1, \forall i \in I$

$\sum_{j \in I} x_{j j}=p$
$I$ : set of nodes, $p$ : number of facilities, $f_{i}$ : frequency of demand at node $i, d_{i j}$ : distance between nodes $i$ and $j, x_{i j}=1$ if facility $j$ serves $i,=0$ otherwise.

These results yielded 30 potentially sustainable and profitable locations (Fig. 8), similar to those of previous studies. Martin and Shaheen (2011) found that carsharing is highly correlated with the urban environment such as public transit and pedestrian infrastructure. Costain et al. (2012) mentioned that members are more likely to use carsharing vehicles from within a distance of $1 \mathrm{~km}$. Celsor and Millard-Ball (2007) found that carsharing is closely related to car ownership and locations are characterized by large parking spaces and high population density. The locations proposed in this paper are mostly near places with a high daytime population density, such as major stations and terminals, are easily accessible and have high walking rates.

Effect of carsharing on carbon dioxide emission reduction

Alleviating vehicle-related air pollution requires traffic demand management. Sheng and Tang (2013) presented 


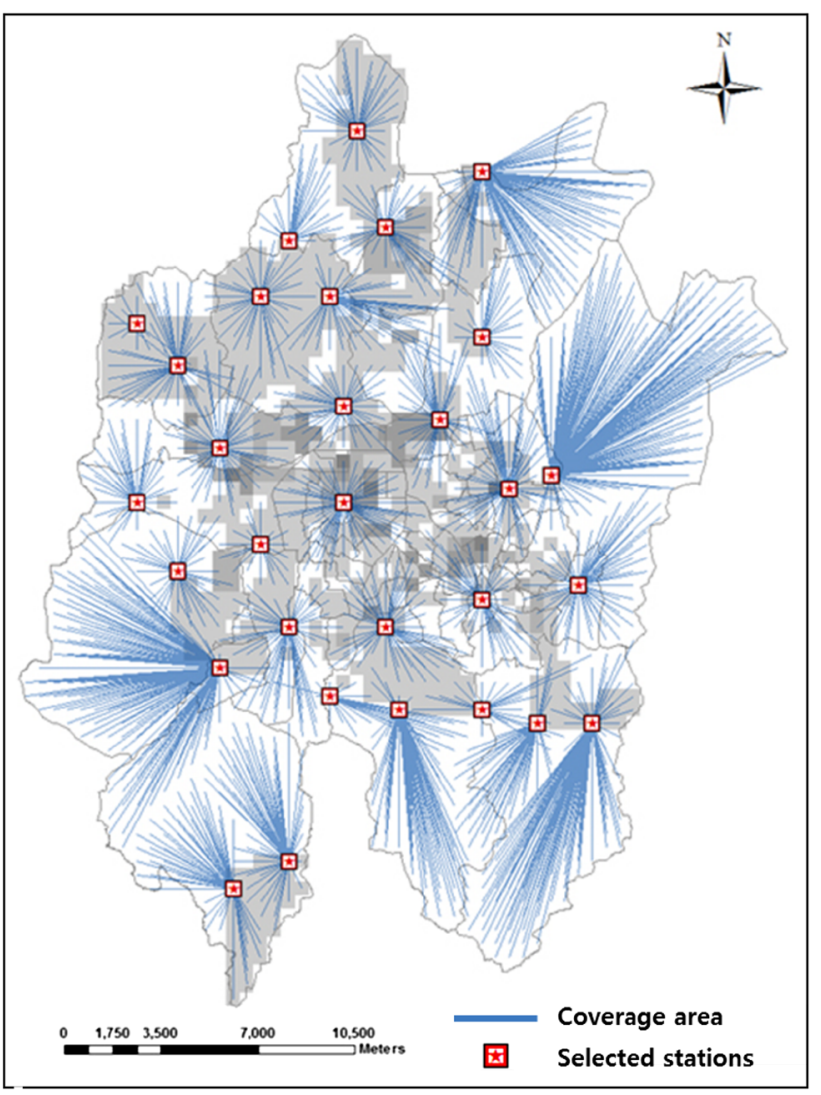

Fig. 8 Potentially sustainable and profitable locations for carsharing companies

Table $2 \mathrm{CO}_{2}$ emission reductions (2013 vs. 2020)

\begin{tabular}{lll}
\hline Year & 2013 & 2020 \\
\hline Carsharing participation rate (\%) & 7.75 & 20.0 \\
$\begin{array}{l}\text { Avg. } \mathrm{CO}_{2} \text { reduction from carsharing } \\
\text { (tCO2eq) }\end{array}$ & 82,348 & 225,253 \\
$\mathrm{CO}_{2}$ emission from personal cars in & $10,775,622$ & $11,884,063$ \\
$\quad \begin{array}{l}\text { Daejeon (tCO2eq) } \\
\mathrm{CO}_{2} \text { emission reductions from carsharing } \\
\text { over that from personal car }(\%)\end{array}$ & 5.31 & 13.37 \\
\hline
\end{tabular}

traffic-related air pollution maps to protect the cultural heritage of Macao. Generally, carsharing is beneficial because it decreases movement distance by changing mobility habits and, in turn, potentially reduces $\mathrm{CO}_{2}$ emissions. A high percentage of carsharing members either postpone buying a private car or decide not to buy one and choose other means of transportation, such as bicycling, walking, or public transport (Shaheen et al. 2009; Shaheen et al. 2006). Martin and Shaheen (2011) found that carsharing reduces huge amounts of greenhouse gases. Thus, we investigated the correlation between optimal carsharing locations and $\mathrm{CO}_{2}$ emission reduction, as well as the effect of carsharing on emission reductions, in Daejeon city. In order to calculate $\mathrm{CO}_{2}$ emissions, we need to establish the relative reduction in vehicle miles or kilometers traveled (VMT or VKT) by shared cars and the latent carsharing participation rate when the carsharing locations are properly and sufficiently distributed. Cooper et al. (2000) estimated the mileage reduction from carsharing at $7.3 \%$. In 2013, a mileage reduction of $39.6 \%$ was predicted for Daejeon (Lee and Lee 2013). Based on data from the Greenstart members, as well as current carsharing members in Daejeon city, carsharing membership was expected to reach $7.75 \%$ (119,868 people) in 2013. If carsharing locations are properly distributed, the number could increase to $20.1 \%$ as of 2030 . From these results, CO2 emission reductions from carsharing were estimated at 62,070 tCO2eq. as of 2013. CO2 emissions are predicted to decrease further to 172,923 tCO2eq by 2020 (Table 2). These reductions represent 5.31 and $13.37 \%$ over the predicted $\mathrm{CO} 2$ emissions from personal car users in Daejeon for $2013(10,775,622$ tCO2eq $)$ and 2020 $(11,884,063$ tCO2eq), respectively. In other words, carsharing could reduce $5.31 \%$ of $\mathrm{CO} 2$ emissions in 2013 and $13.37 \%$ by 2020 . Consequently, determining optimal carsharing locations is very significant in maximizing the carsharing operation rate and, in turn, reducing $\mathrm{CO}_{2}$ emissions. Thus, carsharing is an innovative strategy for traffic demand management that could alleviate air pollution.

\section{Conclusion}

Increasing car ownership is believed to worsen traffic congestion, air pollution, and parking problems. Many countries worldwide, including those in North America and Europe, have begun encouraging carsharing as an alternative to car ownership as it helps to alleviate air pollution and traffic congestion. Carsharing offers two benefits: the convenience of a personal car and a low price compared with traditional car rental. Thus, it can serve as a new, easily accessible transportation system.

In the early stage, most carsharing companies determined their service locations through trial and error. However, this practice has not led to the desired outcomes, especially in small cities, or in some Asian countries that are unfamiliar with carsharing systems. In other words, the chosen locations may not be sustainable or profitable for the companies. Thus, the investigation of key indicators is very important, and several such indicators must be considered to establish a successful carsharing service in most small cities, or in Asian countries.

In this study, the urban Korean city of Daejeon was selected for a case study. Cities such as Daejeon have a 
low-quality public transportation system, and commercial areas are dispersed throughout the city. A GIS tool was used to determine optimal carsharing locations in Daejeon. As key indicators, eight spatial elements were considered. These indicators were weighted using the AHP technique. Notably, their ranking was highly sensitive to the weights assigned to various criteria. Then, by using the locationallocation model in the network analysis module, 30 suitable locations were determined as being potentially sustainable and profitable for carsharing companies. $\mathrm{CO}_{2}$ emission reduction from carsharing was calculated to investigate its correlation with optimal carsharing locations. In this study, $\mathrm{CO} 2$ emission reduction from carsharing was estimated at 62,070 tCO2eq for 2013 and 172,923 tCO2eq for 2020. These amounts were, respectively, 5.31 and $13.37 \%$ over the predicted $\mathrm{CO} 2$ emissions from personal car users in Daejeon for the same years.

Car ownership is not expected to decrease in the short term despite its negative effects such as traffic congestion, air pollution, and parking problems. Carsharing is not the ultimate solution to reducing car ownership in many Asian countries, particularly Korea. In addition, the selected indicators in this study may have nothing that differentiates them from those in the pioneering cities. This is because carsharing in Korea has just started and is yet to become popular in small Korean cities. Even though carsharing data have now been accumulated, the data obtained are not sufficient to validate our study. However, according to Celsor and Millard-Ball (2007), each city has different indicators-one-person households, commute mode shares, and neighborhood characteristics, for example. Hence, a more systematic approach was applied to determine optimal service locations. Despite the limited availability of carsharing data, this study demonstrated that adequately addressing location determination issues is very important for the sustainability of carsharing services and that air pollution can also be alleviated by changing people's lifestyle choices. Further studies need to focus on the relationship between optimal carsharing locations and $\mathrm{CO}_{2}$ emission reduction by lower-emission carsharing vehicles, such as electric vehicles and gasoline-electric hybrid cars. In addition, a validation study with sufficient carsharing data needs to be performed as a future work.

Acknowledgments This research was supported by a grant from the Daejeon Development Institute.

\section{References}

Atabi F, Moattar F, Mansouri N, Alesheikh AA, Mirzahosseini SAH (2013) Assessment of variations in benzene concentration produced from vehicles and gas stations in Tehran using GIS. Int J Environ Sci Technol 10:283-294
Catalano M, Casto BL, Migliore M (2008) Car sharing demand estimation and urban transport demand modeling using stated preference techniques. Eur Transp 40:33-50

Celsor C, Millard-Ball A (2007) Where does carsharing work? Using geographic information systems to assess market potential. Transp Res Rec J Transp Res Board 1992:61-69

Cervero R, Tsai Y (2004) City carshare in San Francisco, California: second-year travel demand and car ownership impacts. Transp Res Rec J Transp Res Board 1887:117-127

Chan Y (2004) Location, transport and land-use. Springer, New York. ISBN 3-540-21087-3

Cooper G, Howes D, Mye P (2000) The missing link: an evaluation of carsharing Portland Inc. Workshop Report Prepared for Public Policy Research, Oregon Department of Environmental Quality, and CarSharing Portland Inc

Correia G, Antunes A (2012) Optimization approach to depot location and trip selection in one-way carsharing systems. Transp Res Part E 48:233-247

Costain C, Ardron C, Habib KN (2012) Synopsis of users' behaviour of a carsharing program: a case study in Toronto. Transp Res Part A 46:421-434

Ion L, Cucu T, Boussier JM, Teng F, Breuil D (2009) Site selection for electric cars of a car-sharing service. World Electr Veh J 3, ISSN: 2032-6653

Jorge D, Correia G (2013) Carsharing systems demand estimation and defined operations: a literature review. Eur J Transp Infrastruct Res 13(3):201-220

Kim K (2012) Zipping around NYC: Carsharing in New York City

Lee SH, Lee JB (2013) Analyzing the environmental effect of carsharing. J Korean Soc Environ Technol 14(5):369-375

Leveque F, Moosa MM (2013) Voice of future car sharing customer: it's all about wholly sharing and partly pairing. Frost and Sullivan

Liao CH, Chang CL, Su CY, Chiueh PT (2013) Correlation between land-use change and greenhouse gas emissions in urban areas. Int J Environ Sci Technol 10:1275-1286

Litman T (2000) Evaluating carsharing benefits. Transp Res Rec J Transp Res Board 1702:31-35

Martin EW, Shaheen SA (2011) Greenhouse gas emission impacts of carsharing in North America. IEEE trans Intell Transp Syst 12(4):1074-1086

Nouri J, Maghsoudlou B, Aboushahab Z (2013) Utilization multi attribute decision making models for spatial prioritization and environmental decision making in new towns. Int J Environ Sci Technol 10:443-454

Rodier C, Shaheen SA (2003) Carsharing and carfree housing: predicted travel, emission, and economic benefits. Presented at 82nd Annual Meeting of the Transportation Research Board, Washington, DC

Shaheen SA, Cohen AP (2007) Growth in worldwide carsharing. Transp Res Rec J Transp Res Board 1992:81-89

Shaheen SA, Martin E (2010) Demand for carsharing systems in Beijing, China: an exploratory study. Int J Sustain Transp 4(1):41-55

Shaheen SA, Wright J, Sperling D (2002) California's zero-emission vehicle mandate. Transp Res Rec J Transp Res Board 1791:113-120

Shaheen SA, Cohen AP, Roberts JD (2006) Carsharing in North America: market growth, current developments, and future potential. Transp Res Rec J Transp Res Board 1986:116-124

Shaheen SA, Cohen AP, Chung MS (2009) North American carsharing: 10-year retrospective. Transp Res Rec J Transp Res Board 2110:35-44

Sheng N, Tang UW (2013) Risk assessment of traffic-related air pollution in a world heritage city. Int J Environ Sci Technol 10:11-18 
Tuzkaya UR (2009) Evaluating the environmental effects of transportation modes using an integrated methodology and an application. Int J Environ Sci Technol 6(2):277-290

Vlachopoulou M, Silleos G, Manthou V (2001) Geographic information systems in warehouse site selection decisions. Int J Prod Econ 71:205-212
Zhao D (2010) Carsharing: a sustainable and innovative personal transport solution with great potential and huge opportunities. Frost and Sullivan 